Mediterránea Ser. Biol. (1990), n. ${ }^{\circ}$ 12. Pág. 5-26

\title{
TIPOLOGÍA Y CARTOGRAFÍA POR FOTOINTERPRETACIÓN DE LOS HUMEDALES DE LAS CUENCAS DEL DUERO Y DEL TAJO
}

\author{
por \\ J. M. ${ }^{a}$ REY BENAYAS, C. PÉREZ PÉREZ, \\ F. GONZÁLEZ BERNÁLDEZ, Y M. ZABALETA FRANCO
}

\section{RESUMEN}

El concepto de humedal se ha ampliado en los últimos años, así como los factores que intervienen en su génesis y funcionamiento, cobrando una especial relevancia el papel de las aguas subterráneas.

La fotointerpretación, auxiliada por las observaciones en el campo, permite inventariar y tipificar según las características dominantes estas zonas. En este artículo se explican las diferencias entre áreas de recarga y descarga de agua subterránea según los humedales presentes, en función de su morfología y distribución, vegetación asociada, presencia o ausencia de enclaves salinos, fenómenos geomorfológicos (tales como los complejos «bodón-montículo»), microrrelieve (gilgai), etcétera.

Las conclusiones permiten diferenciar cuatro grandes grupos de humedales: charcas de recarga, descargas lineales locales, descargas difusas intermedias y descargas difusas regionales.

PALABRAS ClAVE: Humedales. Cartografía. Fotointerpretación. Tipología.

Dpto. Interuniversitario de Ecología. Universidad Autónoma y Complutense de Madrid. 28049 Madrid.

\section{SUMMARY}

In recent years, the concept of wetlands has broadened, as have the factors contributing to their genesis and maintenance, especially those related to groundwater. Photointerpretation, aided by field observations, permits their classification and typification according to dominant characteristics.

The present paper describes the differences between groundwater discharge and recharge areas in the wetlands under study according to their morphology, distribution, associated vegetation, presence or absence of salt-bed enclaves, geomorphological phenomena such as «hummock-hollow» complexes and gilgai microrelief, etc.

The conclusions distinguish four large groups of wetlands: recharge ponds, local lineal discharges, intermediate diffuse discharges, and regional diffuse discharges.

Reywords: Wetlands. Mapping. Photointerpretation. Typology. 


\section{INTRODUCCIÓN}

El objetivo de este trabajo es la utilización de la fotointerpretación y de las observaciones en el campo en áreas de muestreo, para el inventario y cartografía de los humedales (wetlands), en territorios relativamente extensos. El concepto de humedal utilizado está orientado a la conservación y gestión de recursos fundamentalmente biológicos, correspondiendo por tanto a criterios amplios de definición: se considera como tal toda anomalía positiva de la humedad de la superficie de significativo tamaño y duración, que no es ni un lago, ni un río (González Bernáldez, 1988; Bernáldez y Montes, 1988). La diferencia con los lagos se puede establecer en función de la profundidad: $2 \mathrm{~m}$. (profundidad máxima de arraigo de la vegetación emergente), como hacen Cowardin et al. (1979) y otros autores, al separar los wetlands de los lagos o «deepwater habitats». La anomalía hídrica puede estar producida por descargas de sistemas acuiferos, por inundaciones superficiales debidas a la presencia de capas impermeables que dificultan la infiltración, o por combinación de ambas causas.

\section{ÁREAS DE ESTUDIO}

\section{Duero}

Está situada en la cuenca terciaria de la submeseta Norte, en la cuenca del Duero, y constituye una banda limitada al Norte por el río Duero, al Sur por el afloramiento del zócalo rocoso (parte paleozoica, granito y gneísica del pedimento del Sistema Central), al Este por el meridiano $4^{\circ} 30^{\prime}$, coincidiendo groseramente con la trayectoria S-N del río Voltoya, y al Oeste por el meridiano $5^{\circ} 04^{\prime}$, más o menos coincidiendo con el interfluvio Tormes-Trabancos. Constituye un rectángulo de $60 \times 98 \mathrm{Km}$. que, litológicamente, está constituido por materiales detríticos, fundamentalmente arcosas miocenas, aunque presenta localmente depósitos de arenas cuaternarias y «rañas» pliocuaternarias (IGME, 1982; IGME, 1986).

En conjunto, el territorio representa una rampa suavemente inclinada en dirección Sur-Norte (dirección que toman los afluentes del Duero). Entre esos afluentes se presentan sectores de carácter más o menos endorreico.

Los materiales terciarios detríticos sirven de asiento a un gran acuífero regional denominado Los Arenales (IGME, 1980).

El uso del suelo está predominantemente dedicado a agricultura cerealista de secano, con importantes enclaves de regadío de aguas subterráneas (remolacha, girasol), quedando la vegetación natural reducida a enclaves o territorios vestigiales, como los depósitos de arenas cuaternarias (plantados en su mayor parte con Pinus pinea y Pinus pinaster) y las áreas de descarga de acuíferos: terrazas y proximidades de cursos de agua, prados, juncales y encharcamientos más o menos extensos que, por su humedad, y a veces salinidad, dificultan el cultivo.

\section{Tajo}

Está situada en la depresión o valle del Tajo, coincidiendo con la denominada «facies Madrid» de la cuenca de Madrid, que corresponde a los terrenos 
arcósicos procedentes de la destrucción de los materiales (principalmente granitos y gneises) de las Sierras de Guadarrama y Gredos. Sus límites meridionales son la fase de transición a los materiales evaporíticos, mientras que al Norte, el zócalo cristalino aflorante constituye un borde del acuifero prácticamente impermeable. El límite oriental lo constituye el río Jarama y por el Oeste, la zona se extiende hasta Talavera de la Reina (Toledo), ya que a partir de aquí la cuenca de Madrid da paso a la de Campo Arañuelo (Herrera, 1987), en el punto denominado por Hernández Pacheco «Estrecho de Talavera». Abarca una superficie algo menor de 6.000 kilómetros cuadrados, alcanzando a veces profundidades de 2 y $3 \mathrm{Km}$.

La red hidrográfica principal la constituyen los ríos Jarama, Manzanares, Guatén, Guadarrama, Aulencia, Perales y Alberche, todos ellos en la margen derecha del disimétrico valle del Tajo.

La zona más deprimida, con una altitud aproximada de 360 m. s.n.m., se sitúa en el extremo suroeste (confluencia Alberche-Tajo, en las proximidades de Talavera de la Reina), mientras que los terrenos más elevados se encuentran al nordeste, en el interfluvio Jarama-Manzanares, con valores de altitud que oscilan alrededor de los 760 m. s.n.m.

Administrativamente, la zona de estudio se encuentra enmarcada en parte de las provincias de Madrid y Toledo.

En la figura 1 se representa un mapa de situación de las áreas descritas.

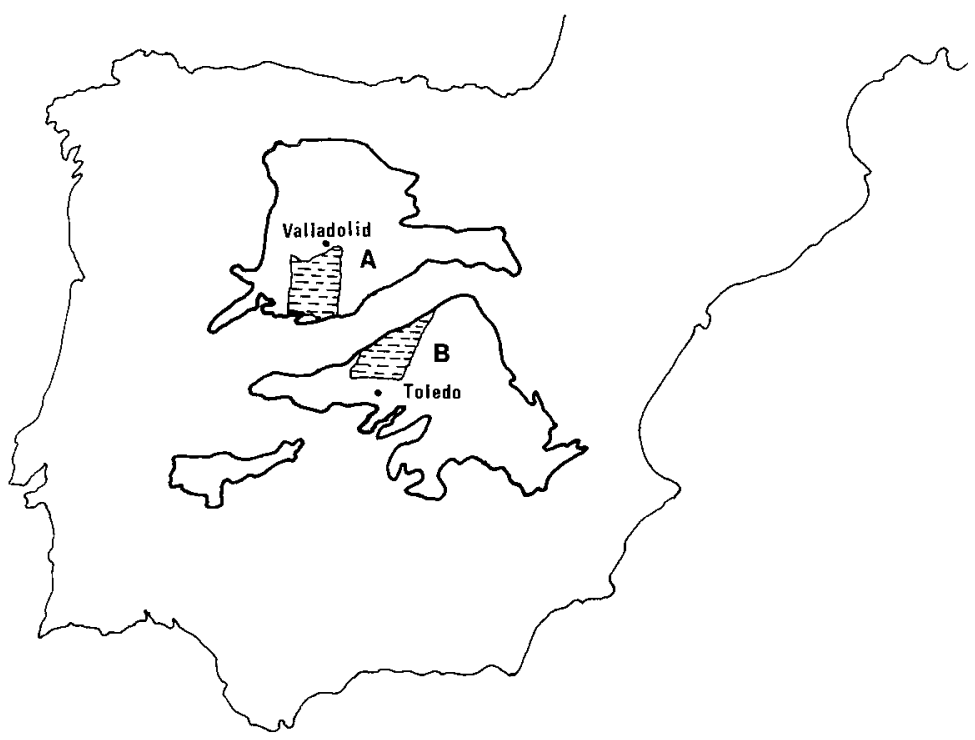

Figura 1.- Mapa de situación de las áreas fotointerpretadas. Se escogieron dos transectos de naturaleza principalmente detrítica, que ofrece ciertas ventajas para el estudio de los modelos hidrogeológicos, en las denominadas Mesetas Norte y Sur españolas, donde existe un gran contraste entre los humedales investigados y el terreno circundante. A. Transecto de la cuenca del Duero. B. Transecto de la cuenca del Tajo. 


\section{MATERIAL Y MÉTODOS}

\section{Fotointerpretación}

Los vuelos utilizados en la fotointerpretación son los pancromáticos escala 1:18000 de 1983-84 para la provincia de Madrid, y de 1977 para el resto del territorio. Las características observadas se refieren a:

- Complejos de vegetación freatofítica e hidrofítica, en áreas no labradas por exceso de humedad (humedales), donde se diferencian: formaciones de Scirpus lacustris y Typha spp., prados, juncales, arbustos y árboles freatofíticos.

- Láminas de agua: charcas, lagunas y áreas inundadas.

- «Salgüeros» o enclaves de suelos salinos, con manifestaciones tales como precipitados, eflorescencias de sal y erosión del horizonte A (Benáldez et al., 1989).

- Morfología: forma de las áreas húmedas no labradas, microrrelieve de éstas (gilgai, complejos alternantes de charcas-montículos, etc.).

- Zanjas de drenaje.

\section{Comparación con observaciones sobre el terreno}

Los resultados de la fotointerpretación se han comparado con observaciones de campo, y con un muestreo que abarcaba el mismo territorio y que comprendió:

- Inventarios de vegetación en parcelas de $10 \times 10 \mathrm{~m}$. distribuidas por todo el área de estudio (185 en el Duero, 198 en el Tajo).

- Muestras de suelo compuestas a partir de 5 testigos de sonda de $20 \mathrm{~cm}$. de profundidad, que se tomaron en la mayoría de la citadas parcelas (156 en el Duero, 144 en el Tajo). En estas muestras se analizaron: la conductividad eléctrica, $\mathrm{pH}, \mathrm{Na}^{+}, \mathrm{K}^{+}, \mathrm{Ca}^{++}, \mathrm{Mg}^{++}, \mathrm{SO}^{=}, \mathrm{Cl}^{-}, \mathrm{CO}^{-}$y $\mathrm{CO} 3 \mathrm{H}^{-}$, en el filtrado de la solución suelo-agua 1:10 tras agitación mecánica.

- Puntos de agua (pozos y manantiales), distribuidos en el área de estudio, en los que se determinó: el nivel piezométrico, datos químicos anteriormente mencionados y las caracteristicas de funcionamiento.

Además se han empleado los datos piezométricos de Martí Vallbona et al. (1979).

\section{RESULTADOS}

Mediante la fotointerpretación se realizaron mapas escala 1:50000 de los humedales del área estudiada, de los que se presentan fragmentos reducidos en los figuras $2,3,4$ y 6 , y un esquema simplificado del conjunto en la figura $5 a$ para el caso del Duero y en la figura 5 b para el Tajo.

\section{Correspondencia con áreas de recarga y descarga}

Estas categorías hidrogeológicas son las que corresponden mejor con los sectores distinguidos en el mapa de humedales (cuadro 1). Las áreas de recarga, que están caracterizadas por la dirección descendente del componente ver- 


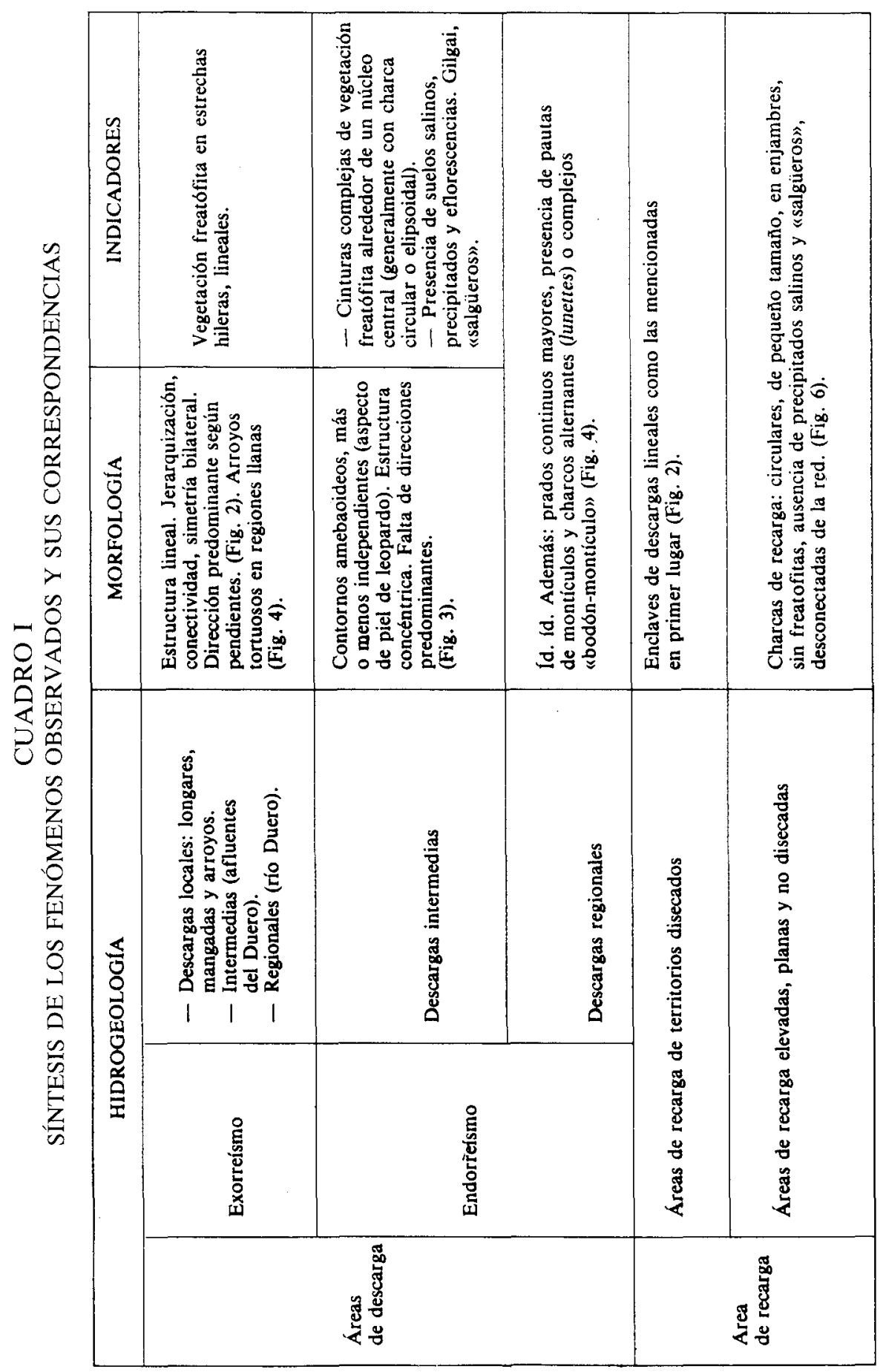




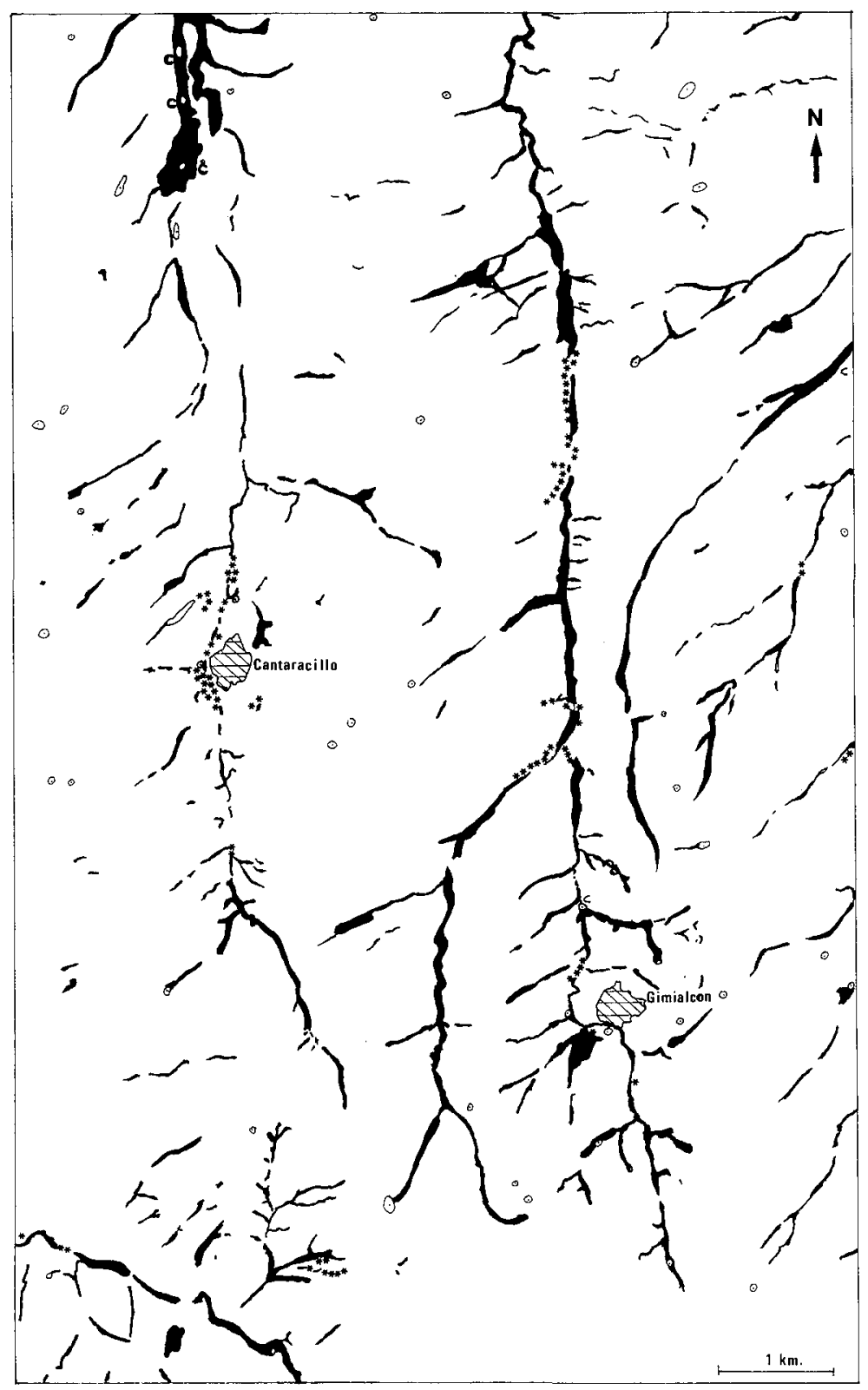

Figura 2.- Área representativa de descargas locales en la región de Cantaracillo (Salamanca). Se pueden observar las características de linealidad, jerarquización y simetría bilateral de estos humedales.

Símbolos: Céspedes y juncales. $\square$ Charcas.

Sotos. - Caozos. 


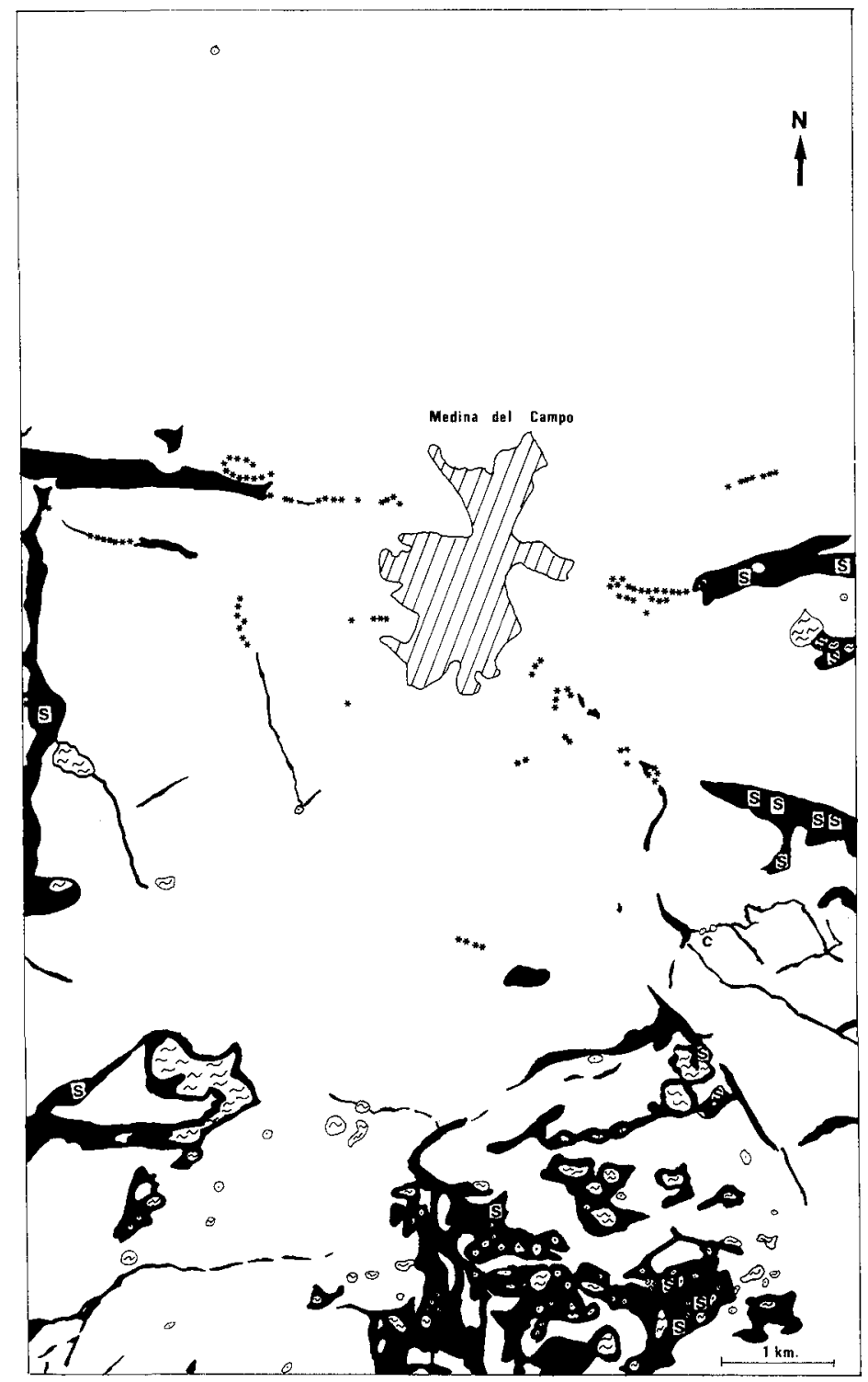

Figura 3.- Área representativa de humedales difusos debido a la descarga de flujos subregionales o intermedios de agua subterránea, situada al sur de Medina del Campo (Valladolid). Se aprecian las características de no jerarquización, existencia de eflorescencias salinas y multitud de láminas de agua que dan la apariencia del moteado de una piel de leopardo. La ausencia de humedales por encima de Medina del Campo se debe a la existencia de depósitos pliocuaternarios.

Símbolos:

Céspedes y juncales.

[-8 Láminas de agua. [5] Caozos.

s Eflorescencias salinas. 


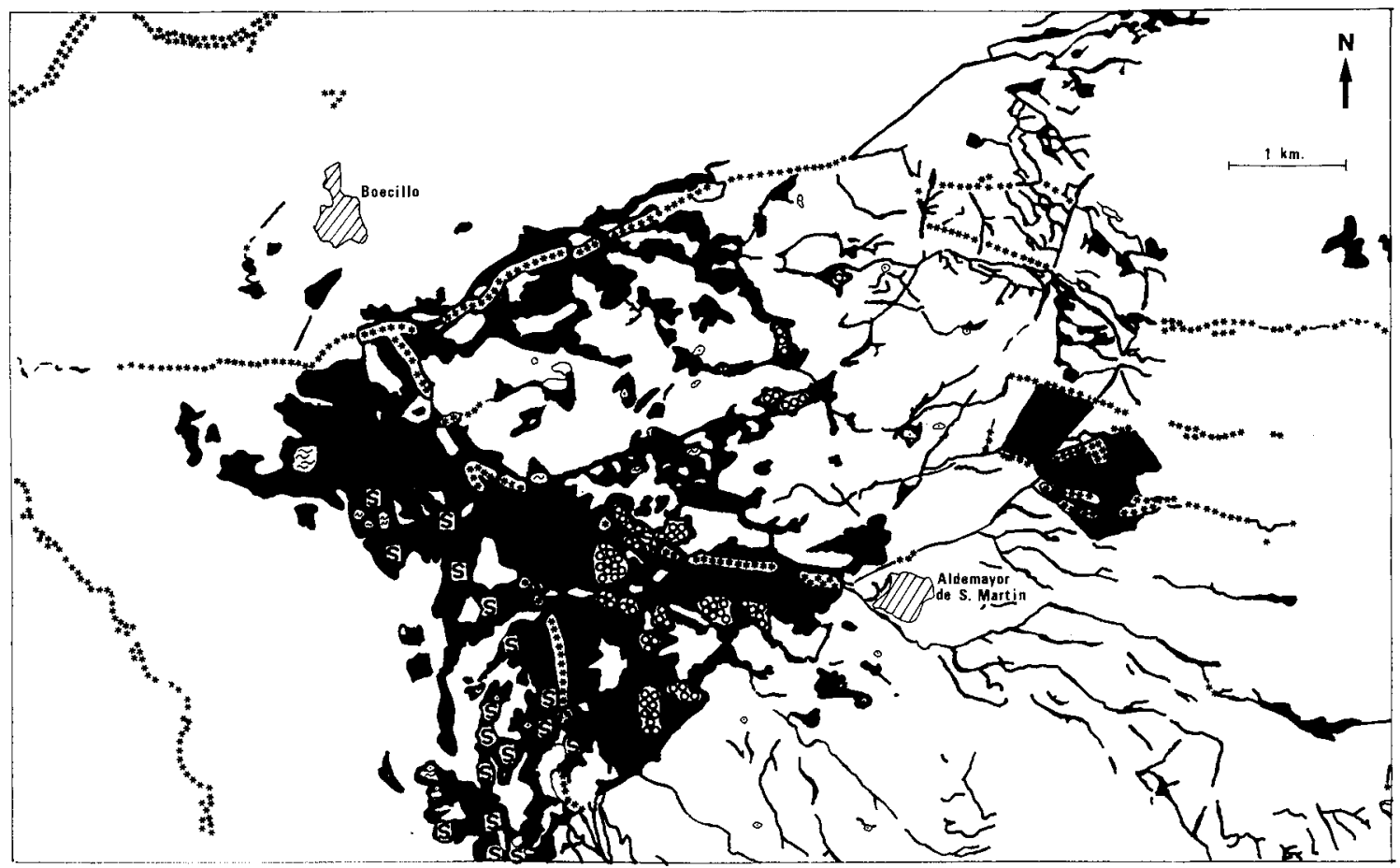

Figura 4.- Área representativa de descargas regionales, en la región de Aldeamayor de San MartínBoecillo (Valladolid). Aparte de las características propias del resto de los humedales difusos (no jerarquización, eflorescencias salinas, etc.) se pueden observar la enorme extensión de estos sistemas, los complejos «bodón-montículo» y la tortuosidad de los sistemas exorreicos (parte derecha de la figura).

Símbolos:

Céspedes y juncales. $\ldots$ Sotos.

Láminas de agua.

[s] Eflorescencias salinas.

$[00$ Complejos «bodón-montículo». 


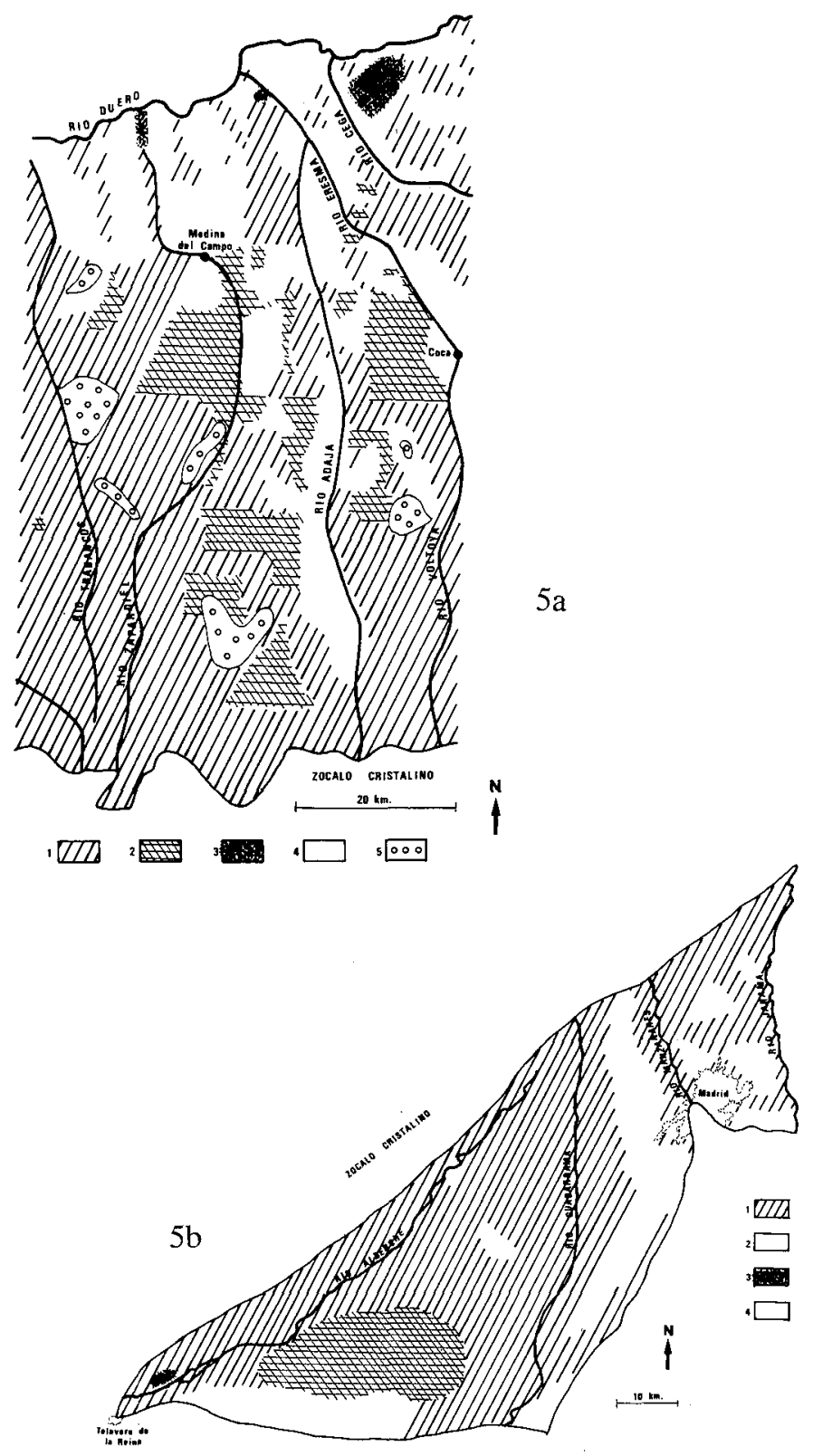

Figura 5.- Esquemas simplificados según la tipología morfológica dominante de los humedales. a) Cuenca del Duero. Símbolos como en la figura $5 \mathrm{a}$.

1.-Descargas lineales. 2.-Descargas difusas subregionales. 3.-Descargas difusas regionales. 4.-Áreas sin humedales. 5.-Áreas con lagunas y charcas de recarga. b) Cuenca del Tajo. Símbolos como en la figura $5 b$.

1.-Descargas lineales. 2.-Descargas difusas subregionales. 3.-Descargas difusas regionales. 4.-Áreas sin humedales. 


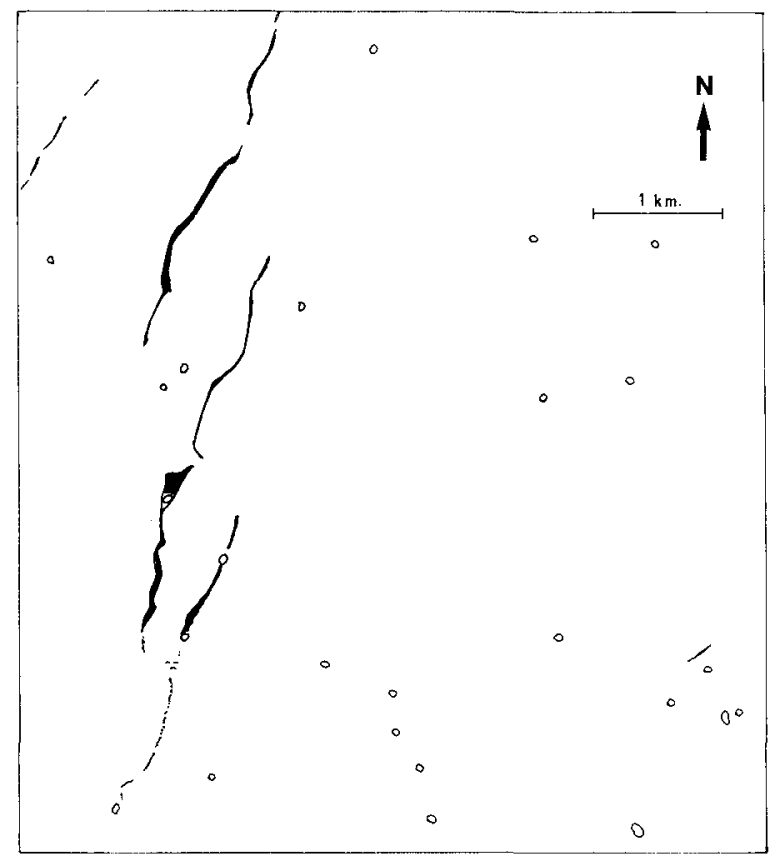

Figura 6.- Zona representativa de áreas de recarga, topográficamente altas y relativamente planas, donde los únicos humedales presentes son las denominadas charcas y lagunas de recarga.

Símbolos:

Céspedes y juncales.

[0] Charcas de recarga.

tical del agua subterránea (Tóth, 1968; Fetter, 1980; Bernáldez et al., 1987), tienen condiciones hidrogeoquímicas y de vegetación muy diferentes a las de las áreas de descarga, caracterizadas por la dirección ascendente del componente vertical del flujo de las aguas subterráneas. Es en estas últimas donde se localizan la mayoría de los humedales.

La comparación con la topografía del terreno y con las circunstancias del flujo de aguas subterráneas (IGME, 1980; González Bernáldez et al., 1987a), pone de manifiesto ciertas correspondencias entre características y distribución de los humedales y los tipos de descarga.

\section{Descargas lineales}

Las características de relieve con pendiente más pronunciada, que implican un paisaje más disecado en lomas y vaguadas, condicionan características de exorreísmo, que se manifiesta por la presencia de humedales en forma de vaguadas o juncales muy alargados, jerarquizados y en dirección de la pendiente (Figura 2). Muchas de estas formaciones están recorridas por cursos de agua más o menos pasajeros o efímeros. Estos humedales corresponden a mecanismos de descarga de sistemas de flujos cortos, es decir, descargas locales, 


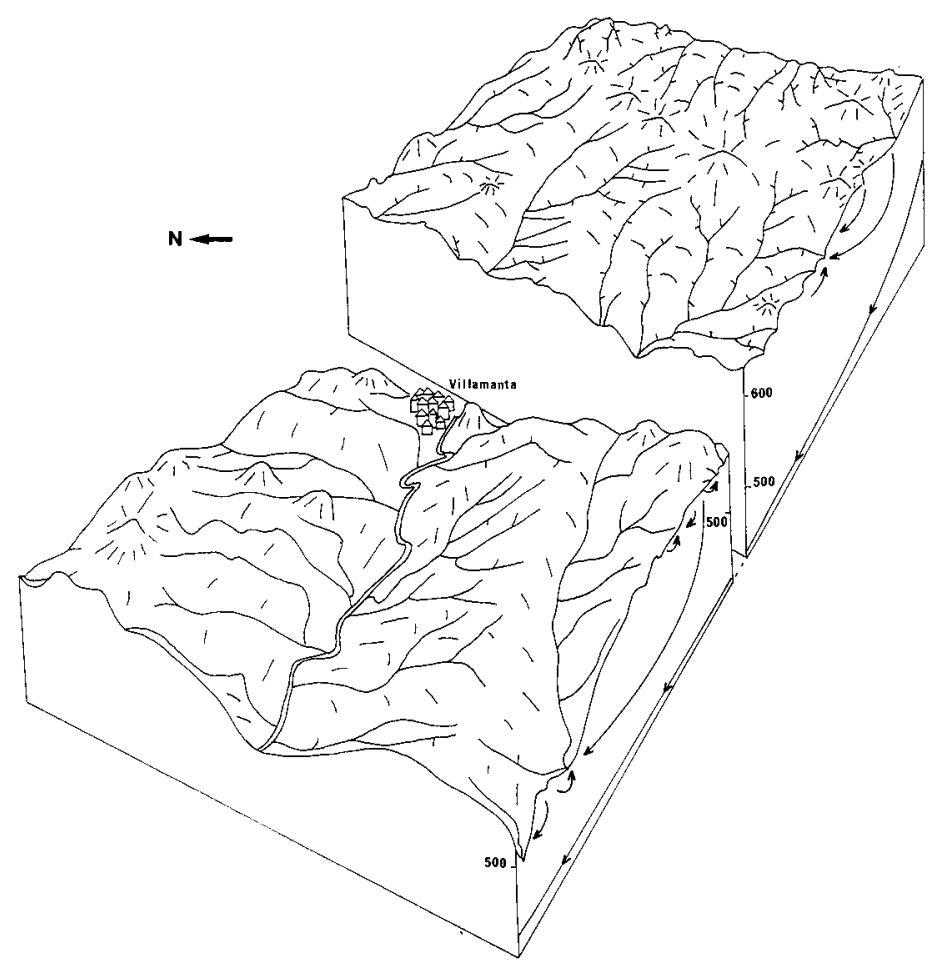

Figura 7.- Bloque diagrama representativo de paisajes disecados, con fuerte pendiente topográfica de flujos locales, originándose descargas lineales caracterizadas por su exorreismo, jerarquización y contigüidad de áreas de recarga y descarga. Esta figura corresponde a situación de paisaje real en Villamanta (Madrid).

cuyas áreas de recarga (topográficamente elevadas) y de descarga (topográficamente deprimidas) son adyacentes (Tóth, 1963), (Figura 7). Son las circunstancias de la disección del relieve las que condicionan la presencia de múltiples sistemas locales de flujo, mientras que excluyen la presencia de sistemas de flujos intermedios, presentes en otras áreas.

Las formaciones con vegetación higrofítica, correspondientes la mayor parte a descargas locales en este territorio, son de varios tipos que difieren principalmente por el grado de incisión que presentan en el terreno, desde barrancos hasta vaguadas de perfil transversal muy suave. También es variable el grado de conservación de la vegetación, siendo el área de pendientes relativamente fuertes donde más frecuentemente se conserva la vegetación ribereña leñosa (sotos). La inspección en el terreno revela que las especies presentes son Fraxinus angustifolia, Populus alba, Salix atrocinerea y Salix salvifolia, especialmente. Por el contrario, en zonas de relieve más suave, las alineaciones están formadas por prados-juncales, que proceden de la alteración antrópica de la vegetación anterior. Los datos de los inventarios de estos tipos de descarga (González Bernaldez et al., 1987a) indican que, al igual que las leñosas anterior- 


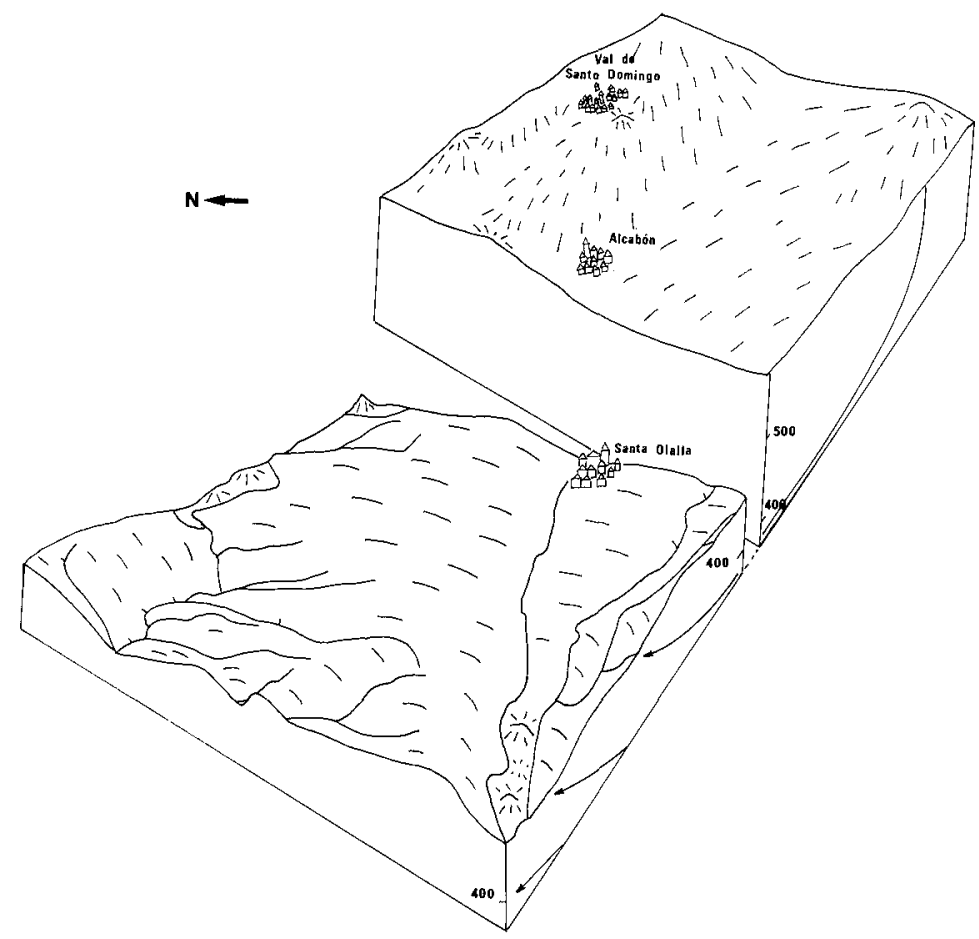

Figura 8.- Bloque diagrama representativo de paisajes llanos, donde dominan sistemas de flujos intermedios, originándose descargas de carácter más o menos endorreico, difusas, con neta separación entre áreas de recarga y descarga. Esta figura corresponde a situación de paisaje real en Val de Santo Domingo-Santa Olalla (Toledo).

mente citadas, se trata de especies glicofíticas: Agrostis castellana, Rumex angiocarpus, Senecio jacobea, Juncus inflexus, etc.

En el Duero, estos prados alargados, que pueden estar recorridos por cauces de agua pasajeros, están alternando normalmente entre superficies cultivadas con cereales. Esto les ha valido el nombre de «entrepanados» (Salamanca), mientras que su forma justifica los nombres vernáculos de «mangadas»o «longares» (Alcázar y otros, en prensa). Pueden presentar láminas de agua en forma de ensanchamientos del cauce central («caozos», «cadozos» o «cagorzos», Salamanca), lo que constituye un tránsito a las charcas no conectadas de las descargas difusas en áreas endorreicas.

En ambos acuíferos la anchura del prado puede ser mínima, quedando reducida a una hilera de vegetación freatofítica, de 1-3 $\mathrm{m}$. de anchura.

Las descargas locales, caracterizadas en nuestros territorios de estudio por su forma lineal, pueden tener una densidad relativamente elevada, como en el borde meridional en el caso del Duero y en la mayor parte del territorio del Tajo, con más pendiente del pedimento, donde alternan áreas de recarga y descarga adyacentes de tamaños relativamente pequeños a causa de la disección 
del terreno (Figuras 2 y 7), o presentarse relativamente aisladas en el interior de grandes áreas de recarga (descargas en áreas de recarga).

En la mayoría de los casos, y en contraste con las formaciones que se examinarán luego, dichas formaciones lineales corresponden a descargas locales y presentan las siguientes características: forma alargada, orientadas en direcciones predominantes, jerarquización y conectividad, estructura con simetría bilateral, vegetación freatofítica formando bandas longitudinales relativamente estrechas, pudiendo suponer su superficie (en el acuífero del Duero) el 2,2\% del terrritorio en que están circunscritas, según Bernáldez et al. (1989).

\section{Descargas difusas}

Otros humedales detectados (praderas-juncales, áreas encharcadizas, bodones, lavajos y lagunas), corresponden a manifestaciones del agua subterránea en áreas más llanas del pedimento (Figuras 3, 4 y 8), caracterizadas por un endorreísmo más o menos acusado, claramente menos patente en el caso del Tajo.

En su expresión más característica (Figuras 3 y 4) se trata de extensos prados, con la capa saturada lo suficientemente cerca de la superficie como para que pueda ser evaporada a través de los sistemas conductores de la vegetación (criptohumedales o «hidden seepages») (González Bernáldez et al., 1985). La vegetación leñosa, que en muchos casos serían especies de Tamarix, ha sido totalmente aniquilada por el uso ganadero, estando formada por juncos y especies herbáceas pratenses. Su composición varía, en función especialmente de su posición en el gradiente del campo de flujo de agua subterránea (González Bernáldez et al., 1987a), desde formaciones de Festuca arundinacea fenas, Hordeum secalinum, etc., a saladares con Suaeda Vera, pasando por juncales con Juncus acutus, Juncus maritimus, etc.

Hidrogeológicamente estas descargas difusas, que coinciden con los territorios endorreicos del pedimento, corresponden en su mayoría a descargas intermedias del acuífero regional. En este tipo de descargas, las áreas de recarga y descarga no ocupan las posiciones más altas y más bajas respectivamente de la cuenca, intercalándose entre ellas una o más elevaciones y depresiones topográficas (Tóth, 1963).

Las descargas difusas regionales, que ocupan las posiciones más deprimidas de la superficie del acuífero, y que presentan unas características semejantes pero con algunos rasgos diferenciadores (Figura 4, cuadro 1), sólo se presentan en los confines distales (septentrionales) del acuífero del Duero, y en una pequeña zona al sur del acuífero del Tajo.

Son características típicas de los humedales asociados con estas descargas difusas las siguientes:

Contorno irregular ameboide en las fotos áreas, en manchas más o menos inconexas, sin orientación dominante, con lenta transición entre vegetación xerofítica e higrofítica y simetría radial heterogénea. Los cursos de agua poco encajados, tales como arroyos, presentan trayectorias tortuosas y divagantes, como se puede apreciar en la parte derecha de la figura 4. El conjunto asemeja en ocasiones al moteado de una piel de leopardo (Figura 3). Hemos calculado, en el caso del Duero, en un $8,6 \%$ la superficie que ocupan estos humedales en áreas de descarga de agua subterránea. 


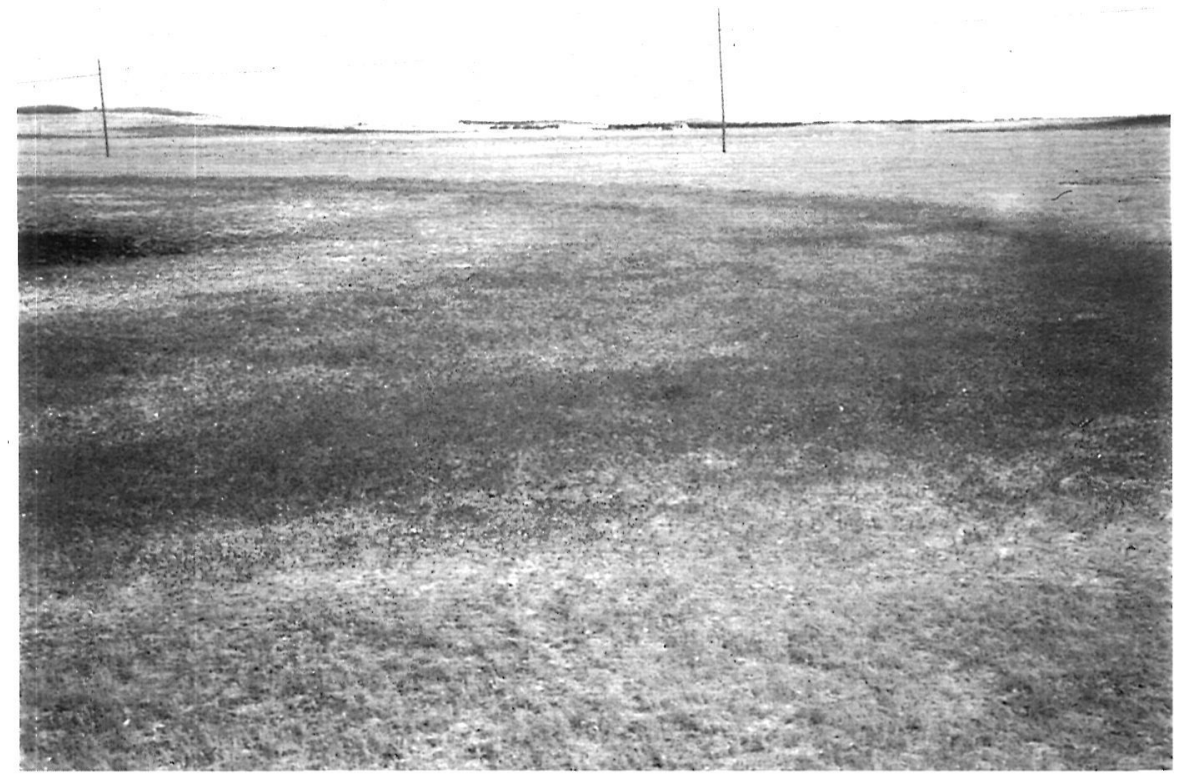

Figura 9.-Cinturones concéntricos de vegetación alrededor de un bodón, el cual ocupa la parte más deprimida del humedal, característicos de áreas de descargas difusas. Palacios Rubios (Ávila).

La estructura más frecuente es la presencia de una parte más deprimida, aproximadamente en el centro del humedal, donde se presenta una lámina de agua groseramente circular. A partir de ésta, la pendiente - muy suave- se eleva hasta llegar a los terrenos no influidos por el agua subterránea (cultivados). Esta estructura condiciona bandas características de vegetación aproximadamente concéntricas (Figura 9).

A partir del centro ocupado por la masa de agua más o menos permanente («bodón», «lavajo» o «laguna») con cinturones de vegetación freatofítica (Scirpus lacustris y Scirpus maritimus) se pasa a una banda de plantas relativamente independientes del agua subterránea (Scirpus holoschoenus), que forman la cintura más xerofítica. Entre ambas existe una zona característica en la que, por distancia crítica de la superficie a la zona capilar, se produce migración y acumulación de sales, dando lugar a áreas con suelos alcalinos o salinos (según los lugares), llamadas localmente «salgüeros» o «toscales», con presencia de precipitados salinos y eflorescencias (González Bernáldez et al., 1987a). Con frecuencia se presentan también pequeñas áreas donde tiene lugar la destrucción y erosión del horizonte A, que da lugar a la exposición del horizonte $\mathrm{B}$ arcilloso, en cuya superficie llaman la atención las eflorescencias salinas, característicamente blancas (Figura 10). Esas áreas suelen estar orientadas de forma que denuncian la importancia de la erosión eólica (a causa de la escasa cobertura vegetal, pues sólo especies tales como Puccinellia festuci- 


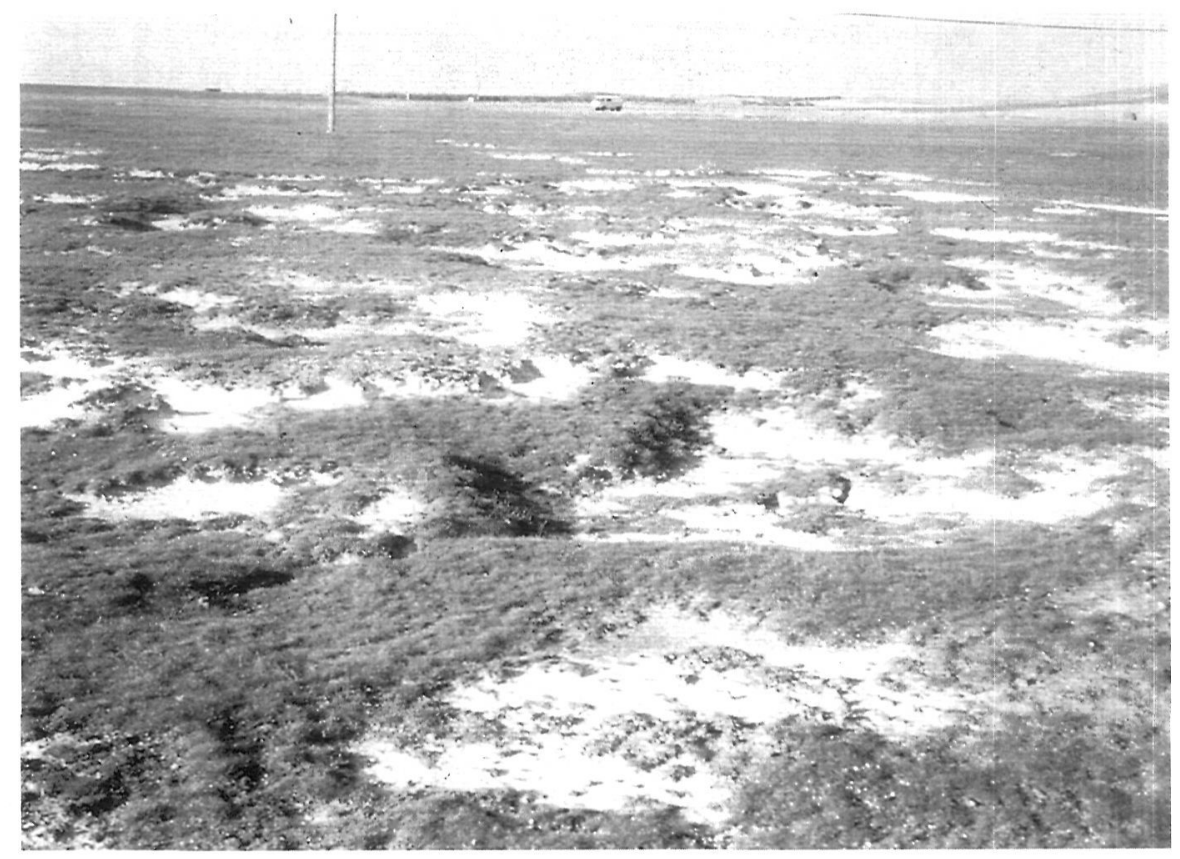

Figura 10.-Enclave salino en Martín Muñoz de las Dehesas (Segovia). Se aprecia el fuerte microrrelieve ondulado o gilgai, así como la erosión fragmentaria del horizonte A del suelo, que deja al descubierto las eflorescencias salinas, característicamente blancas.

formis, Plantago maritima y Camphorosma monspelliaca, entre otras, pueden colonizar fragmentariamente esas áreas a las que ofrecen precaria protección).

La presencia frecuente de un fuerte gilgai o microrrelieve ondulado en estos terrenos facilita el ataque eólico en los flancos de los montículos de esa formación.

Las áreas donde se presentan los mosaicos de descargas difusas tienen, además de su carácter llano, la particularidad de presentar algún tipo de contrapendiente en su borde distal respecto a la dirección del componente horizontal del flujo regional del acuífero, es decir, «aguas abajo» del mencionado flujo. En el Duero este tipo de ligeras elevaciones o contrapendientes, que limitan las manchas de humedales por el Norte, es visible en los pares estereoscópicos y, muchas veces, sobre el terreno.

En el acuífero del Tajo, estas descargas ocupan una porción muy pequeña del territorio (ver Figura $5 b$ ), presentándose poco desarrolladas y muy alteradas por la intervención humana, no siendo tan claro su aspecto «difuso» como en el caso del Duero. A pesar de ello se incluyen en este apartado, por tratarse de descargas de flujos intermedios, con densidad de drenaje más escasa y menos jerarquizada que la de las restantes comarcas, y relieve más llano, lo que le confiere cierto carácter endorreico.

Los datos recogidos simultáneamente con la fotointerpretación, indican que las áreas de descargas difusas, correspondientes a sistemas intermedios de 
flujo, muestran diferencias edafoquímicas e hidrogeoquímicas muy acusadas respecto a las descargas lineales, destacando la mineralización de aguas y suelos (Bernáldez et al., 1987; González Bernáldez et al., 1987a; Bernáldez et al., 1988).

Como se ha indicado, la inmensa mayoría de esas descargas difusas corresponden a descargas intermedias del acuífero regional, manifestaciones de los flujos subregionales, que no ocupan, sin embargo, las depresiones máximas de la superficie del acuífero. Las descargas regionales, por el contrario, que sí están situadas en las depresiones más bajas del sistema, se presentan, en el acuífero del Duero, en la vecindad del río del mismo nombre (Figura 4 y área de trama densa en el rincón noreste de la Figura 5a), en la región de Aldeamayor de San Martín y de Boecillo. Los humedales condicionados por esas descargas están separados del río Duero por elevaciones del terreno (albardanes fluviales, depósitos de arenas eólicas o retazos de rañas pliocuaternarias no desmontadas por la erosión). En el caso del Tajo, sólo se dan en el extremo más meridional del acuífero (Figura $5 b$ ), en una pequeña zona muy cercana a Talavera de la Reina.

Además de las características de las descargas difusas ya comentadas, las descargas regionales presentan algunos rasgos propios, debido al carácter exacerbado de su haloquimismo y halofitismo - pues la mineralización del agua subterránea, tras haber recorrido largas trayectorias, es elevadísima (Fetter, 1980; Bernáldez et al., 1987) - y a la importancia del componente vertical ascendente del flujo.

En el acuífero del Duero llama la atención el gran tamaño de las manchas de humedal, que forman superficies muy continuas (Figura 4). También es característica la presencia, en las partes centrales de las manchas, de conjuntos de pequeños montículos y charcas que hemos denominado «complejos bodónmontículo» (Figura 11). Éstos corresponden a pequeñas charcas o bodones, efímeramente encharcados, de unos $5-10 \mathrm{~m}$. de diámetro, que alternan con montículos de aproximadamente el mismo diámetro basal y unos $2 \mathrm{~m}$. de altura, y que parecen corresponder a los materiales extraídos por el agua subterránea y el viento de las citadas depresiones. Es posible que estén emparentados a fenómenos de dunas de limo y arcilla «lunettes» (Tricart et al., 1969), más que a una exacerbación de los fenómenos de ondulación o gilgai de las descargas intermedias. Es muy probable la participación de mecanismos de surgencia puntuales de agua subterránea a causa de un fuerte componente vertical ascendente, tal como se observa en los volcanes de barro o «goteras» (González Bernáldez et al., 1987b), como mecanismo iniciador. La salinidad facilita una vez más la acción eólica, al dispersar la arcilla convirtiéndola en fango fluido. Las depresiones o bodoncillos presentan a veces conexiones ocasionales, pero pueden ser independientes. La existencia de estas pautas de alternancia montículobodón, con la del nivel general del suelo y áreas de erosión del horizonte $\mathrm{A}$ ya comentado, hace que estos territorios presenten un mosaico complejo de vegetación y suelos, donde alternan vegetación marcadamente higrofítica y halófila: Salicornia ramosissima, Juncus subnodulosus, Aeluropus littoralis, etc., con áreas de Suaeda vera en el nivel serial del suelo o vegetación xerohalófita (Puccinellia festuciformis, Plantago maritima, etc.) y montículos donde el efecto del agua subterránea deja de sentirse: Koeleria vallesiana, Teucrium scordium, etc. (González Bernáldez et al., 1987a). Pautas y mosaicos de «bodón- 


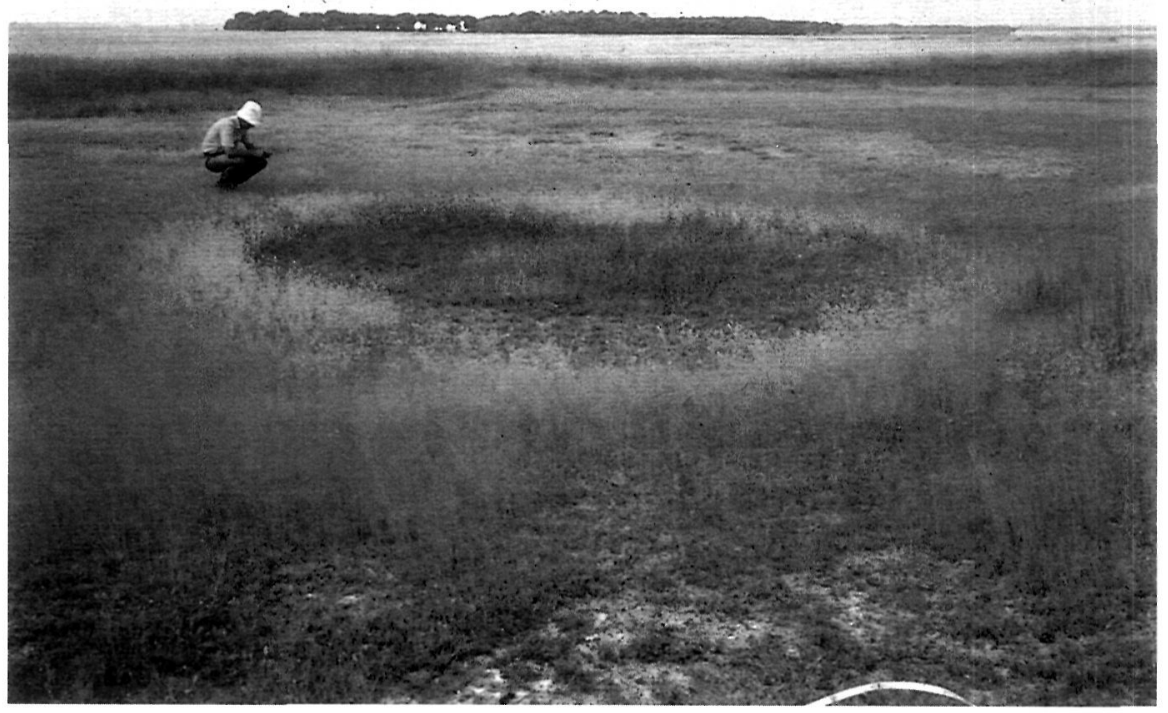

Figura 11.- Complejos «bodón-montículo», característicos del área de descarga del acuífero situado al sur del río Duero, en Aldeamayor de San Martín (Valladollid).

montículo» idénticos se encuentran en el área de descarga regional de Villafáfila, junto a Otero de Sariegos (Zamora).

\section{Cursos de agua y sus terrazas}

Evidentemente, tanto el Duero como sus afluentes, representan descargas del acuífero regional, correspondiendo los segundos (Eresma, Zapardiel, Trabancos, Cega, etc.) a descargas de carácter subregional o intermedio y el Duero, situado en la posición más deprimida de la cuenca, a una descarga regional. Sólo en algunos puntos de sus terrazas, especialmente en los desniveles entre éstas, se presentan manifestaciones del acuífero regional, cartografiables como humedales, como en las amplísimas terrazas de Tordesillas, de hasta $500 \mathrm{~m}$. de anchura.

\section{Áreas de recarga}

Como se ha indicado, los humedales de los territorios estudiados tienen tendencia a concentrarse en las áreas de descarga, más bajas topográficamente y poseedoras de flujo vertical ascendente de agua subterránea.

Grandes extensiones de recarga aparecen prácticamente libres de humedales, en el sentido que se da aquí a la expresión, careciendo de anomalías hídricas positivas que condicionen la presencia de juncales, prados húmedos, ve- 
getación leñosa higrofítica, láminas de agua, charcas, lagunas, encharcamientos, etc. (Figuras $5 \mathrm{a}$ y $5 \mathrm{~b}$ ).

Entre las zonas de recarga más importantes figuran los interfluvios elevados y los depósitos post-terciarios, tanto las rañas como las arenas eólicas muy permeables. Estas últimas tienden a presentarse en alineaciones paralelas a los afluentes del Duero, con trayectorias Sur-Norte. Eso no impide, sin embargo, que ambas formaciones den lugar a áreas de descarga con humedales en los contactos con base terciaria.

Como ya se mencionó, las áreas de recarga incluyen enclaves ocasionales de descargas locales, todas ellas de naturaleza lineal. El humedal genuino de las áreas de recarga son las pequeñas charcas (Figura 6), desconectadas entre sí, que salpican los altos interfluvios planos donde el agua subterránea se encuentra a grandes profundidades. Las características de estas charcas de recarga son las siguientes:

Forma circular. Tamaños pequeños (este carácter mucho más acusado en el Tajo), aproximadamente de 10 a $30 \mathrm{~m}$. de diámetro. Aislamiento de arroyos o de la red de drenaje superficial. No presentan a su alrededor ningún prado húmedo característico de las descargas difusas, ni cinturones de plantas freatofíticas verdaderas (hay Eleocharis palaustris, Glyceria declinata y Pulicaria paludosa, pero no Juncus spp. o Scirpus lacustris). No están asociadas con suelos salinos, ni eflorescencias, ni precipitados, ni presentan vegetación halófita. A diferencia de lo que ocurre con los «bodones» y «lavajos» de los humedales de descargas intermedias, no son sensibles al fenómeno de descenso del agua subterránea debido al riego abusivo. Muchas son simples cubetas o depresiones muy efímeras, siempre secas en verano, que apenas tienen higrófitas. Algunas poseen agua más permanentemente, sin duda no conectada con la del acuífero regional por ser su composición química muy diferente (Canal de Isabel II, 1989). Muchas son por ello fácilmente destruibles por la actual maquinaria agrícola.

Es también característica su presencia en superficies de recarga elevadas, planas, no disecadas, tanto de materiales terciarios como de rañas, formando núcleos o enjambres, con distancias de unos 100 a $400 \mathrm{~m}$. entre ellas. Entre estos complejos destacan los de la región de Cantaracillo, Fresno el Viejo y Cantalapiedra, en Salamanca; Jaraices y Constanzana en Ávila; Nava del Rey, en Valladolid, etc., en el acuífero del Duero, y charcas aisladas en Griñón y Leganés, en Madrid, y Casarrubios del Monte, Ventas de Retamosa y los Cerrebos, en Toledo, en el acuífero del Tajo.

\section{DISCUSIÓN}

La relativa homogeneidad litológica de las áreas y sencillez del sistema de flujos de los acuíferos regionales, permiten establecer una tipología y cartografía de los humedales a escala 1:50000, aprovechando las correspondencias entre características del desagüe superficial y las de las descargas del acuífero regional.

Los sotos y prados lineales del territorio más exorreico, correspondientes a descargas de sistemas locales de flujo y provistos de vegetación glicofítica más o menos conservada (sotos), o transformada por el uso pastoril (prados «entrepanados», «longares», «mangadas», etc.) han recibido ya cierta aten- 
ción en bibliografía ecológica española (Montserrat, 1982; González Bernáldez, 1981), como «ecosistemas de vaguada».

Las descargas difusas correspondientes a sistemas intermedios de flujo, en territorios endorreicos, presentan una estructura fotointerpretable a escala 1:50000, semejante a las lozhbina y zapadina de las estepas euroasiáticas, exhibiendo una estructura concéntrica semejante: limany centrales y aureolas de suelos alcalinos: soloniets (Dobrovolski, 1976; Chemekov, 1972). Áreas de erosión con pérdida del horizonte A y eflorescencias salinas han sido descritas en circunstancias muy parecidas en descargas de la prairie canadiense (Leskiw, 1971).

La oposición entre la parte disecada del territorio, con áreas de recarga y descarga estechas y contiguas, y la parte más llana con descargas difusas y áreas de recarga alejadas, se conocía ya del acuífero de Madrid en la cuenca del Tajo (Canal de Isabel II, 1989). La interpretación de estos fenómenos está en la.gran disección y eficiente avenamiento que los afluentes del Jarama, Manzanares, Guadarrama y parte del Alberche llevan a cabo en la mayoría de la superficie del acuífero de Madrid. Ello condiciona la vigencia en superficie de un sistema de flujos locales, con trayectorias cortas, escasa evolución del agua que descarga en los humedales, y una contínua alternancia de pequeñas áreas de recarga y descarga locales. De esta eficiente disección y encajamiento de la red de afluentes ha quedado relativamente respetada la región de MaquedaSanta Olalla, de relieve más llano y menor encajamiento de la red. En esa área tienen ocasión de desarrollarse sistemas de flujo mayores, con trayectorias más largas, poniéndose de manifiesto fenómenos de flujo regional que no se dan en otras áreas del territorio. En el Tajo, sin embargo, esas descargas difusas comprenden una proporción mucho más reducida de la superficie del acuífero (González Bernáldez et al., 1987a) que en el caso de la cuenca del Duero.

Las descargas difusas correspondientes a la manifestación de los flujos regionales del acuífero, en la zona más deprimida de la cuenca, presentan una morfología muy característica en lo que se refiere al microrrelieve descrito. Pautas de microrrelieve en forma de montículos y pequeñas depresiones semejantes existen en varios tipos de sebkhas, sabkhas o chotts del norte de África, que parecen corresponder a áreas de descarga de aguas mineralizadas en condiciones de mayor aridez (Tricart et al., 1969). En el acuífero de Madrid estas formas sólo aparecen de forma embrionaria, en la laguna de las Torres y Serranillos Playa (Herrera, 1987; González Bernáldez et al., 1987a). Sin embargo, pueden observarse muy desarrolladas cerca de Otero de Sariegos (Zamora), entre las dos grandes «salinas» o lagunas de Villafáfila, al norte del río Duero. Aquí alternan también pequeñas depresiones salinas, inundadas parte del año, con montículos que parecen corresponder a los materiales acumulados por el viento a partir de las depresiones. Fenómenos semejantes se han descrito en humedales de zonas áridas que corresponden probablemente a descargas regionales y subregionales (Tricart et al., 1969). Queda sin dilucidar el posible papel genético de los mencionados volcanes de barro y «goteras», así como la posibilidad de que la destrucción del gilgai por el viento lleve a consecuencias semejantes. En todo caso, el citado microrrelieve tiene gran importancia en la determinación de los tipos de comunidades vegetales y animales, generando una gran heterogeneidad de hábitats salinos, tanto acuáticos como xéricos. 


\section{AGRADECIMIENTOS}

Al proyecto de la CAICYT PB 85-0229-CO2, que sufraga, en parte, estas investigaciones.

\section{BIBLIOGRAFIA}

ALCÁZAR, A.; MARTÍNEZ, A.; REY BENAYAS, J. M., y J. P. RUIZ (en prensa). Toponimia y léxico relacionados con las descargas de aguas subterráneas de la cuenca del Duero. Estudios Geográficos.

BERNÁLDEZ, F. G.; HERRERA, P.; LEVASSOR, C.; PECO, B., y SASTRE, A. (1987). Las aguas subterráneas en el paisaje. Investigación y Ciencia, n. ${ }^{\circ} 127$, pp. 8-17.

BERNÁLDEZ, F. G. \& MONTES, C. (1988). Conservación de especies = Conservación de ecosistemas. El caso de los humedales (wetlands). II Jornadas sobre bases ecológicas para la gestión ambiental. Zaragoza, 13-15 junio, 1988.

BERNÁLDEZ, F. G.; MONTES, C.; HERRERO, P.; BESTEIRO, A. G., y SASTRE, A. (1988). Genetical typology of the Madrid aquifer wetlands. International Symposium on Hydrology of Wetlands in Semiarid and Arid Regions. May, 1988. Seville, Spain.

BERNÁLDEZ, F. G.; REY BENAYAS, J. M.; LEVASSOR, C. y PECO, B. (1989). Landscape ecology of uncultivated lowlands in Central Spain. Landscape Ecology, V. 3, n. ${ }^{\circ}$ 1, pp. 3-18.

CANAL DE ISABEL II (1989). Los humedales del acuifero de Madrid. Inventario y tipologia según su origen y funcionamiento. Comunidad de Madrid.

CHEMEKOV, YU. F. (1972). Metodischeskoe Rukovodstvo po geomorfologicheskim issliedovanijam (Guía metódica de las investigaciones geomorfológicas). Niedra. Leningrado.

COWARDIN, L. A.; CARTER, V.; COLET, F. C., and LA ROE, E. T. (1979). Classification of the wetlands and deepwater habitats of the United States. Fish and Wildlife Service. U. S. Department of the Interior. Washington.

DOBROVOLSKII, V. V. (1976). Geografija Pochv (Geografía edafológica). Provieshchenie. Moscú. FETTER, C. W. (1980). Regional Groundwater Flow, Inc. Applied Hydrogeology. Mersil.

GONZÁLEZ BERNÁLDEZ, F. (1981). Ecologia y Paisaje. H. Blume. Madrid.

- (1988). Typology of wetlands and evaluation of the resources they represent. International Symposium on Hydrology of Wetlands in Semiarid and Arid Regions. May, 1988. Seville. Spain.

GONZÁLEZ BERNÁLDEZ, F.; PÉREZ, C. and, STERLING, A. (1985). Areas of Evaporative Discharges from Aquifers. Journal of Environ. Management, 21: 321-330.

GONZÁLEZ BERNÁLDEZ, F.; HERRERA, P.; SASTRE, A.; REY BENAYAS, J. M. y VICENTE LAPUENTE, R. (1987a). Comparación preliminar de los ecosistemas de descarga de aguas subterráneas de las cuencas del Duero y del Tajo. Hidrogeología y Recursos Hidráulicos. Vol. XI, pp. 19-34.

GONZÁLEZ BERNÁLDEZ, F.; HERRERA, P. y MONTES, C. (1987b). Los volcanes de barro o «salsas». Fenómenos hidrogeológicos de interés ecológico. Anales de Biología, 12 (Biología Ambiental, 3), pp. 3-9.

HERRERA, P. (1987). Aspectos ecológicos de las aguas subterráneas en la facies arcósica de la cuenca de Madrid. Tesis Doctoral. Universidad de Alcalá de Henares.

IGME (1980). Investigación hidrogeológica de la cuenca del Duero. Sistemas n. ${ }^{\circ} 8$ y 12 . Aguas subterrénas. Colección Informe.

- (1982). Mapa Geológico de España E 1:200.000. Hoja 37. (Salamanca).

- (1986). Mapa Geológico de España E 1:200.000. Hoja 29. (Valladolid).

LESKIW, S. A. (1971). Relationship between soils and groundwater in field mapping near Vegreville, Alberta. Thesis. Faculty of Graduated Studies. University of Alberta, Edmonton. 
MARTÍ VALLBONA, B.; LÓPEZ GARCÍA, L., y GÓMEZ DE LAS HERAS, J. (1979). La utilización de los modelos matemáticos en la investigación hidrogeológica de las grandes cuencas sedimentarias. Aplicación al estudio de la cuenca del Duero. II Simposio Nacional de Hidrogeología. Pamplona.

MONTSERRAT RECORDER, P. (1982). Aspectos ecológicos relacionados con la dinámica de sotos y riberas. Anales de Edafología y Agrobiología, XLI, n. ${ }^{\circ}$ 9-10: 2069-2073.

TÓTH, J. (1963). A Theoretical Analysis of Groundwater Flow in Small Drainage Basins. $J$. Geophys. Res. 68 (10): 4795-4812.

- (1968). A hydrogeological study of the Three Hills area, Alberta. Res. Council Alberta Bull. 24: 117 pages.

TRICART, J. et CAILLEUX, A. (1969). Traité de Geomorphologie. IV. Le Modelé des régions séches. Soc. d'Edit d'Enseign. Superieur. París. 